\title{
Master Scholar Award
}

Published online: 14 November 2016

(C) International Association of Medical Science Educators 2016

The Master Scholar Award recognizes an IAMSE member who has a distinguished record of educational scholarship including educational research and/or dissemination of excellent and scholarly approaches to teaching an education. This could include development of multimedia medical educational programs, research in the areas of curriculum design and evaluation, student assessment, or innovative programs and methods.

2016 Award Winner-Sandy Cook, Ph.D.

In June 2006, Dr. Cook joined the Duke-NUS Graduate Medical School in Singapore, as Associate Professor and the Associate Dean for Curriculum Development as well as head of the Medical Education, Research, and Evaluation Department. In 2010, she was promoted to Senior Associate Dean. In 2012, she began working with the Academic Medicine Education Institute (AM. EI), a joint venture with Duke-NUS and SingHealth-Partners in Medicine as Chief of Pedagogy. In 2014, she was accepted into the NUS Teaching Academy Fellows.

Dr. Cook received her Ph.D. from Cornell University in Adult and Continuing Education. Her Master's is in Research Methodology and her Bachelor's in Experimental Psychology, both from Ohio State University. Prior to coming to Singapore, she was the Associate Dean for Curricular Affairs and Senior Research Professional at The University of Chicago Pritzker School of Medicine from 2001 to 2006. Dr. Cook went to Chicago in 1985 to work as an education specialist for the Diabetes Research and Training Center (DRTC), a major NIH grant that was awarded to the University of Chicago in 1976 and continues to be funded. One of the major focuses of that grant has been the translation of diabetes research to patients, physicians, and the community. She continued on that grant and other diabetes-related grants until 2003, when she focused her time on working with Pritzker School of Medicine's faculty to develop scholarly medical education research projects.

Dr. Cook's overall research in Chicago focused on developing and evaluating educational programs throughout the
Division of Biological Sciences; health outcomes research in the area of diabetes, sleep medicine disorders, asthma, and geriatrics; and faculty development efforts in the area of Scholarship of Education. Her work in the area of simulation and clinical assessment grew with the development of a clinical performance center at the University of Chicago for use in teaching and assessing the clinical skills of medical students. Her research efforts have resulted in numerous publications, published abstracts, and one book chapter. Since coming to Singapore, she has focused much of her research on the development, implementation, and impact of team-based learning and faculty development.

She has been a member of the Society of Directors in Research in Medical Education since 2002 and served on the Board of Directors for 5 year. She spent 8 years on the board of the Chicago Asthma Consortium and served as President from 2003 to 2006. She also was the chair of the Curriculum and Evaluation Committee of the 13 Schools Consortium from 2001 to 2006. She currently is a member of the Team-based Learning Collaborative, the International Association of Medical Science Educators, and the Association of Medical Educators of Europe. Sandy is an associate editor for the Medical Science Educator and the Proceedings of Singapore Health Care.

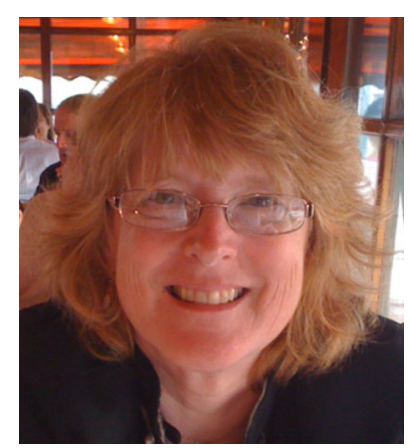

